\title{
ATUAÇÃO DO CONSELHO MUNICIPAL DO MEIO AMBIENTE EM CAMPO GRANDE-MS: LICENCIAMENTO AMBIENTAL
}

ALMEIDA NETO, João Vieira. OLIVEIRA, Ademir Kleber Morbeck. BONONI, Vera Lúcia Ramos.

Programa de Pós-Graduação em Meio Ambiente e Desenvolvimento Regional, Universidade Anhanguera-

Uniderp. Rua Alexandre Herculano, 1400, Jardim Veraneio. CEP 79037-280, Campo Grande (MS).

E-mail: akmorbeck@hotmail.com

\begin{abstract}
Resumo
Os conselhos com gestão participativa são um importante mecanismo de inclusão popular, permitindo que a sociedade civil faça parte de decisões que afetem seu cotidiano nas mais diferentes vertentes. Dessa maneira, este trabalho procura demonstrar a atuação do Conselho Municipal do Meio Ambiente de Campo Grande, durante sete anos de existência, apresentando dados que contribuam para a melhoria da gestão ambiental participativa. Junto à Secretaria Municipal do Meio Ambiente foram levantados processos submetidos ao Conselho Municipal, no âmbito do Sistema Municipal de Licenciamento e Controle Ambiental, no período de abril de 1999 a julho de 2007. O Conselho Municipal do Meio Ambiente avaliou 33 processos de licenciamento, principalmente obras viárias e de recuperação de fundo de vale, ampliando as exigências compensatórias para o licenciamento, porém sem acompanhamento pós-licença dos empreendimentos, com prejuízo das conquistas ambientais exigidas no licenciamento. Concluiu-se que o licenciamento participativo realizado significa um avanço democrático que poderá ser melhorado com a prática e aperfeiçoamento de instrumentos legais.
\end{abstract}

Palavras-chave: Conselhos municipais; Governança; Licenciamento ambiental.

\begin{abstract}
The councils with participative administration are important mechanisms for public involvement, allowing civil society to participate in decisions that affect its daily lives in many different aspects. Thus, this work aims at analyzing the performance of the Environmental County Council of Campo Grande, during seven years of existence, presenting data that may contribute to the improvement of the participative environmental administration. We have analyzed cases from Local Environmental Secretariat presented to the Environmental County Council, in the context of the Local Licensing and Environmental Control, fromApril 1999 to July 2007. The Environmental County Council of Campo Grande analyzed 33 licensing requests, mainly of construction of roads and recovery of the bottom of the valley, increasing the compensation requirements for licensing. It is also clear that there is no follow-up after the licenses have been granted to undertakings, loosing many of the environmental gains required for getting the licenses. The conclusion is that the participative licensing may be understood as a democratic advance that may be improved with the practice and enhancement of legal instruments.
\end{abstract}

KEYwORDs: Local councils; Governance; Environmental licensing. 


\section{INTRODUÇÃO}

O processo de urbanização, decorrente da revolução industrial, transformou os centros urbanos, levando a uma aglomeração de pessoas em áreas cada vez menores. A evolução é diferente em países desenvolvidos, onde ocorreu há mais tempo, possibilitando a estruturação do espaço de uma maneira mais racional. Já nos países em desenvolvimento, é mais recente, ocorrendo de forma acelerada e normalmente gerando uma série de problemas ambientais (ROLNIK, 1995; CEZARE, 2009). De acordo com Ferreira (2000), a década de 1960 levou a um crescimento desordenado em cidades do Terceiro Mundo, sem infraestrutura adequada para suportar o aumento de sua população de uma maneira ordenada, o que provocou impactos ambientais negativos.

No Brasil, o processo aconteceu durante o século XX, principalmente após a proclamação da República, e se tornou mais intenso com a Revolução de 1930, com a migração de populações de áreas rurais para as cidades, sendo consolidado na década de 1950, no governo de Juscelino Kubitschek (CEZARE, 2009).

Mas esse crescimento acelerado em cidades sem infraestrutura adequada causou uma série de problemas, tanto sociais como ambientais, levando a uma perda de qualidade de vida nas grandes metrópoles. Para evitar ou diminuir os problemas que surgem em decorrência de um crescimento não planejado, a gestão ambiental de cidades e municípios é uma ação fundamental.

De acordo com Philippi Jr. et al. (2004b), o processo consiste em administrar os ecossistemas naturais e sociais, buscando a preservação dos recursos naturais e o equilíbrio entre o homem e a natureza. Cezare (2009) coloca que é necessário um sistema que promova o desenvolvimento urbano e ambiental, pois o ambiente é um "bem comum".

Para atingir esse objetivo, Dowbor (1993) coloca que os problemas locais devem ser resolvidos localmente, não ficando na dependência de instâncias políticas que não compreendem o que está ocorrendo, descentralizando o sistema. Cezare (2009) afirma que, para assegurar a participação das comunidades e do poder local, deverá ocorrer uma gestão integrada, por meio de conselhos deliberativos, e uma das formas para se atingir esse objetivo é através da governança, uma nova maneira de pensar a gestão compartilhada democrática.

Para Gonçalves (2005), governança seria a forma como o poder é exercido na adminstração dos recursos, visando ao desenvolvimento na gestão pública. Slomski et al. (2008) a classifica como um conjunto de princípios comuns considerando temas como liderança, integridade, compromisso e transparência, visando à qualidade de vida da sociedade. Levando-se em consideração a questão ambiental, Cezare (2009) coloca que governança é um processo pelo qual ocorre o diálogo democrático entre todos os atores que fazem parte da questão ambiental, visando alcançar o desenvolvimento sustentável.

Gonh (2007), porém, afirma que a prática da governança ainda está em formação, o que torna necessário estudar com mais profundidade o método, envolvendo a sociedade civil e política. Para Cezare (2009), os conselhos gestores seriam os instrumentos mais adequados para o exercício da governança, pois nessa estrutura ocorre a relação entre sociedade e Estado.

No Brasil, o sistema de gestão participativa começa com a Lei Federal n. ${ }^{\circ}$ 6.938, de 31 de agosto de 1981, estabelecendo a Política Nacional de Meio Ambiente, por meio da criação do Sistema Nacional do Meio Ambiente - Sisnama, composto por órgãos e entidades ambientais. Com a promulgação da Constituição Federal de 1988, ocorre a legitimação na participação da sociedade nas políticas públicas (CEZARE, 2009).

Esses conselhos deliberativos, formados principalmente após a promulgação dessa Constituição, propiciam a articulação e negociação entre os diversos grupos de interesse, levando à participação da sociedade civil na tomada de decisões e tornando difícil, ao governo, mudar ou interromper tais ações e decisões, devido à pressão da sociedade, que participou de tais discussões (CARVALHO, 
2003; CEZARE, 2009).

Porém, apesar de sua importância para a questão da qualidade de vida dos municípios, na maior parte deles não ocorre uma participação da sociedade atavés dos conselhos. De acordo com IBGE (2005), em apenas $34 \%$ dos municípios existe um conselho municipal, a maior parte inativa. Philippi Jr. et al. (2004a) colocam que a participação da sociedade civil organizada é fundamental para o sistema de manutenção da qualidade de vida e a falta de conselhos é um impedimento para atingir-se tal objetivo.

Alguns conselhos, como coloca Furriela (2002), se dedicam primordialmente a processos de licenciamento ambiental. A maioria envolve conflitos de grupos com interesses variados, podendo gerar maior ou menor impacto ambiental, a serem compensados e minimizados, sendo decisões que afetam direta ou indiretamente toda sociedade - tornando necessária a criação de mecanismos de controle para minorar os efeitos danosos causados pelas atividades humanas (OLIVEIRA et al., 2008).

O licenciamento ambiental no Brasil, seguindo modelos de outros países e o crescimento da conscientização ecológica, foi implantado a partir da Lei da Política Nacional do Meio Ambiente (Lei n. ${ }^{\circ}$ 6.938/1981) e reforçado pela Constituição Federal de 1988. Governo federal, Estados e municípios, baseados na legislação, passaram a criar os seus Conselhos de Meio Ambiente, com composição diversificada, mas procurando sempre chegar à paridade entre o número de conselheiros da sociedade civil e entidades públicas (BREDARIOL e VIEIRA, 1998), sendo alguns conselhos deliberativos (com poder de decisão) e outros, consultivos (sem poder de decisão).

Mato Grosso do Sul, em consonância com a Política Nacional de Meio Ambiente, promulgou diversas normas legais, referentes ao assunto, como a Lei n. $^{\circ}$ 1.067, de 5 de junho de 1990, que dispõe sobre o Conselho Estadual de Controle Ambiental - Ceca, e a Lei n. ${ }^{\circ} 1.140$, de 7 de maio de 1991, que reorganiza a estrutura básica do Poder Executivo e estabelece as competências da Secretaria Estadual do Meio
Ambiente, preparando o Estado para atuar no Licenciamento Ambiental.

Baseado na legislação federal e estadual e na Resolução 237/97 do Conselho Nacional do Meio Ambiente-Conama, a Prefeitura Municipal de Campo Grande também estabeleceu seu processo de licenciamento ambiental, para empreendimentos e atividades de impacto local (BUAINAIN, 1998). O Conselho Municipal de Meio Ambiente - CMMA foi criado pela Lei n. ${ }^{\circ} 2.924$, de 20 de outubro de 1992, condição básica para o Sistema de Licenciamento Ambiental. Esse Conselho tinha caráter consultivo e de assessoramento a administração municipal, tendo sido reconhecido pela Lei Orgânica do Município (Lei n. ${ }^{\circ} 3.176$, de 11 de julho de 1995). A Lei n. ${ }^{\circ} 3.613$, de 30 de abril de 1999, institui o Sistema Municipal de Licenciamento e Controle Ambiental - Silan, criando antes o Fundo Municipal de Meio Ambiental - FNMA, a ser gerenciado pelo conselho. Por essa lei, o conselho passou a ser responsável pela deliberação de processo de licenciamento ambiental.

Além da transformação do conselho consultivo em deliberativo, a composição do conselho foi modificada. Originalmente criado com 11 membros, em 1992, em que 4 pertenciam à sociedade civil, 1 ao governo federal, 1 ao governo estadual e 4 ao poder público municipal. Porém, esse conselho não chegou a ser empossado.

Em 1995 foi modificada a composição, que passou, por lei, a contar com 17 membros, sendo 8 de instituições públicas, incluindo representantes da Fundação Universidade Federal de Mato Grosso do Sul - FUFMS e da Secretaria de Estado do Meio Ambiente, Cultura e Turismo - Semact. No período considerado neste trabalho, a sociedade civil foi representada pela Associação Brasileira de Engenharia Sanitária - Abes, Centro de Documentação e Apoio aos Movimentos Populares - Cedampo, Organização Não-Governamental Ecologia e Ação - Ecoa, Fundação Neotrópica de Conservação da Natureza, Instituto dos Arquitetos do Brasil - IAB, Ordem dos Advogados do Brasil-OAB, Instituto Brasileiro do Meio Ambiente e dos Recursos Naturais Renováveis 
- Ibama, Sindicato Rural de Campo Grande, Sindicato de Médicos Veterinários do Estado de Mato Grosso do Sul - Sindivet e Associação dos Engenheiros Agrônomos de Mato Grosso do Sul - Aeams, com a mesa-diretora do conselho eleita pelos seus pares e nomeada pelo prefeito. Assim, o primeiro Conselho Municipal do Meio Ambiente foi efetivamente implantado, com a publicação no Diário Oficial, em 4 de junho de 1996.

Em 2007, nova lei ampliou o número de componentes do conselho para 21 membros, ficando então 9 representantes da sociedade civil e 12 do poder público. Os nove representantes da Sociedade Civil organizada foram classificados em três grupos (entidades de defesa do ambiente, profissionais liberais e setor empresarial). Para o exercício de 2007-2009 foram indicados a Fundação para Conservação da Natureza de Mato Grosso do Sul - Fuconams, Fundação Biótica, Associação Bálsamo (entidades ambientais), Conselho Regional de Arquitetura e Engenharia-Crea, Sociedade Sul-Matogrossense dos Médicos Veterinários - Somvet, OAB (profissionais liberais), Sindicato da Habitação e Condomínios Secovi, Sindicato Rural de Campo Grande e a Federação das Indústrias de Mato Grosso do SulFiems (setor empresarial).

Embora com importante atuação ambiental, muitas vezes, na mídia, o enfoque relativo a esses conselhos tem sido a demora dos processos de licenciamento, com opiniões favoráveis ou desfavoráveis ao licenciamento. A demora é considerada por alguns como um entrave burocrático ao desenvolvimento. Do ponto de vista legal, em todo o Brasil existem ações do Ministério Público contra alguns licenciamentos ambientais. De modo geral, o Ministério Público tem uma posição desfavorável ao licenciamento ambiental municipal e aos estudos de impacto ambiental simplificados, alegando despreparo de técnicos e pressão política mais direta sobre os conselheiros.

Levando-se em consideração que os conselhos com gestão participativa são um importante elo da sociedade civil com o poder público (SÃO PAULO, 1993; JACOBI, 1999, 2004, 2006), é necessário conhecer melhor a atuação desses conselhos e, dessa maneira, este trabalho procura demonstrar a atuação do Conselho Municipal do Meio Ambiente de Campo Grande na área de licenciamento, durante sete anos de existência, apresentando dados que contribuam para a melhoria da gestão ambiental participativa.

\section{Procedimentos metodológicos}

A cidade de Campo Grande, localizada na serra de Maracajú, Região Centro-Oeste, é capital do Estado de Mato Grosso do Sul, fundada há mais de 111 anos por colonizadores mineiros, aproveitando os campos de pastagens nativas da região dos Cerrados. Foi planejada em meio a uma vasta área verde, com ruas e avenidas largas, relativamente arborizadas e, por causa da cor avermelhada de sua terra, recebeu a alcunha de Cidade Morena. O município ocupa uma superfície total de $8.096,1 \mathrm{~km}^{2}$, com $154,4 \mathrm{~km}^{2}$ de área urbana, e sua população é de aproximadamente 790 mil habitantes (CAMPO GRANDE, 1999).

Na Secretaria Municipal de Meio Ambiente, foram avaliados 33 processos submetidos ao Conselho Municipal do Meio Ambiente de Campo Grande, no âmbito do Silam, no período de abril de 1999 a julho de 2007. Os processos foram classificados por:

- tipo de atividade do empreendimento

a) extração de areia e basalto; b) recuperação de áreas degradadas, urbanização de fundo de vales e obras viárias e, c) empreendimentos diversos - polos industriais, empresariais e loteamentos;

- instituição de origem do relator;

- proponente; e

- condicionantes agregadas pelo Conselho Municipal de Meio Ambiente (ações que devem ser executadas pelos empreendedores e não constavam anteriormente do processo de licenciamento).

Dos 33 processos analisados, 19 foramencaminhados pelo poder público municipal e 14, solicitados pelo Conselho Municipalde Meio Ambiente, por iniciativa de conselheiros que pediram vistas.

Também foi avaliada uma cópia Inquérito Civil n. ${ }^{\circ}$ 014/2005, instaurado pelo Ministério Público Estadual e pelo Ministério Público Federal, visando apurar 
eventual ameaça ou dano ambiental à Unidade de Conservação Parque Estadual Matas do Segredo, em razão da construção de empreendimentos imobiliários, todos a menos de 1.000 (mil) metros da referida UC, ou possíveis irregularidades no licenciamento ambiental. O Inquérito Civil n. ${ }^{\circ}$ 007/1998, referente à urbanização de fundo de vale, proposto pelas mesmas instituições, também foi analisado.

\section{Resultados E Discussão \\ Processos avaliados}

A análise dos documentos demonstra que a maioria dos processos foi encaminhada pela prefeitura, que teve maior interesse na avaliação dos mesmos, indicando que existe a tendência de o poder executivo sempre estar à frente da questão ambiental, para respaldar seus interesses, embora a solicitação de licenciamento de muitos outros empreendimentos tenha ocorrido por iniciativa dos conselheiros e por pressão da comunidade ou da mídia, mostrando uma efetiva participação dos conselheiros, independentemente dos encaminhamentos da municipalidade ou influências de partidos políticos.

Dos processos de licenciamento municipal aprovados pelo Conselho de Meio Ambiente, até o momento, a maioria (dez) tratou de obras viárias e recuperação de fundos de vale, demonstrando a cidade em expansão, com o crescimento do número de veículos e impermeabilização do solo, obrigando a intervenções constantes nos fundos de vale e ocasionando problemas ambientais graves no município. De modo geral esse tipo de ação também afeta a população de baixa renda, instalada nessas áreas de preservação permanente e, com o advento dos projetos, realocada para novas moradias cominfraestrutura adequada, o que traz claros benefícios sociais.

As atividades extrativistas (nove processos no período analisado), de areia e arenito, são atividades econômicas importantes na região, mostrando novamente a cidade em crescimento, com impactos ambientais frequentes, precisando ser monitorados a cada renovação da licença, principalmente os chamados areeiros, que extraem sua matéria-prima principalmente do leito dos cursos d'água.

Portanto, percebe-se que a maior parte das atividades que causam impacto ambiental é de iniciativa e interesse municipal. Isso reforça a necessidade de se garantir o máximo de independência ao Conselho de Meio Ambiente, mantendo-se o processo de eleição direta para as organizações não-governamentais (ONGs) que o compõem e para a mesa-diretora, o que aconteceu até a data da penúltima eleição, com uma tradição de presidentes não-governamentais. Desde 2005, após a criação da Secretaria Municipal do Meio Ambiente, o presidente do conselho é o Secretario de Meio Ambiente, que coincide com um recrudescimento do pedido de vistas dos conselheiros e uma diminuição significativa do número de processos encaminhados ao CMMA pelo Executivo, mostrando um conflito de interesses e disputa de poder.

\section{Conselho Municipal - atuação}

Ocorreu um rodízio entre os membros do Conselho do Meio Ambiente na relatoria dos processos, dando oportunidade a todos de participar e garantindo equilíbrio nas decisões. Considerando ainda que as formações profissionais dos participantes do conselho são variadas, a rotação de relatores permitiu que visões distintas fossem consideradas. A análise indica que a mesma foi exercida tanto por representantes da sociedade civil como por órgãos ligados ao poder público. Entre os relatores, integrantes da Secretaria de Estado do Meio Ambiente, Cultura e Turismo, Fundação Universidade Federal de Mato Grosso do Sul, Ibama, Aeams, Sindivet, Secovi, Sindicato Rural, IAB, Ecoa e Fuconams. Porém, Ibama e Aeams, com cinco relatorias, e IAB, com quatro, foram os relatores com maior participação (42\%), indicando que existe uma concentração em algumas instituições. Em trabalho realizado por Dombrowski (2008), com conselhos municipais do oeste do Paraná, o autor informa que todos os segmentos da sociedade civil participam; porém, o Poder Executivo exerce forte influência na dinâmica de seu funcionamento, determinando a agenda dos conselhos.

Apesar disso, verificou-se a alternância e a 
participação de todos os membros do CMMA, na relatoria ou nas Câmaras Técnicas que auxiliavam o conselheiro relator, constatado na análise das atas e relatórios. Isso é positivo por demonstrar a pluralidade e multidisciplinaridade no processo de análise e discussão dos processos. A iniciativa dos conselheiros em pedir vistas de processos em trâmite no Silam, e que não passariam obrigatoriamente pela análise e deliberação do CMMA, demonstra o nível de interesse e o grau de vigilância que um conselho ambiental democrático e representativo pode exercer no processo de desenvolvimento de sua cidade.

$\mathrm{Na}$ leitura das atas para análise dos processos, foi possível verificar divergência de ideias e convicções, levando muitas vezes a votações pela maioria e não pela unanimidade, prevalecendo sempre os aspectos legais. Portanto, uma assessoria jurídica independente, à disposição do CMMA, seria extremamente útil para o devido esclarecimento e melhor desempenho dos conselheiros.

Embora palco de discussões, são raras as discordâncias entre os membros do conselho. Apenas na 95. ${ }^{\text {a }}$ sessão ordinária de 18/10/2001, durante o processo de licenciamento de postos de combustível em praças e canteiros centrais, e na 143. ${ }^{a}$ sessão extraordinária, para aprovação da urbanização de fundo de vale do córrego Bandeira, foram registrados votos mostrando discordância entre os membros do conselho.

No caso de projeto de urbanização de fundo de vale, o relator já propõe que o conselho monitore a obra, sugerindo o retorno do processo ao CMMA por ocasião da Licença de Instalação (LI); no entanto, a lei do Silam prevê a deliberação do conselho apenas na fase de Licença Prévia (LP). Na sequência, verifica-se que o processo tramitou normalmente na prefeitura, recebendo a LI, sema participação do Conselho do Meio Ambiente, e hoje opera sem a devida Licença de Operação (LO). Seria necessário esse acompanhamento, através da alteração da legislação municipal, para garantir que as medidas propostas de compensação e mitigação de empreendimentos públicos sejam alcançadas. Não há acompanhamento e controle por parte do CMMA das exigências do licenciamento ambiental. A fiscalização pós-licenciamento é fundamental que aconteça, sendo necessário estabelecer um sistema que tenha condições de funcionar, com ou sem a participação do poder municipal, e com o acompanhamento do conselho.

Nesse mesmo processo, o promotor de Justiça instaurou o inquérito civil $n .^{\circ}$ 007/1998. Foi solicitada, ao presidente do CMMA, a qualificação civil de nove conselheiros que haviam participado das deliberações referentes ao processo de licenciamento. Esse fato demonstra a responsabilidade assumida por um conselheiro quando emite e/ou vota um parecer deliberativo sobre determinado processo de licenciamento. Ou seja, qualquer conselheiro está sujeito a ações penais, se o Ministério Público se convencer que houve uso de má-fé. Embora se presuma que o grau de instrução e conhecimento dos participantes de um conselho possa afetar as decisões, a participação de universidades e representantes de associações de classe com formação universitária permite debates e esclarecimentos, não sendo possível desprezar a experiência de qualquer conselheiro.

A análise dos processos mostrou que o principal embasamento para a emissão do parecer dos relatores, além da legislação vigente, foi o parecer da Comissão de Controle Ambiental, composta por técnicos das várias secretarias da prefeitura, que emitem seus pareceres com caráter multidisciplinar e respaldo pelo poder legal que seus cargos lhes conferem. A partir daí os conselheiros relatores analisam o empreendimento não somente a partir de seu conhecimento técnico pessoal, se for o caso, mas também através de sua visão de cidadão, incorporando a essa análise o caráter de pertinência e importância para a sociedade que será impactada, positiva e/ou negativamente. Para o funcionamento do conselho, a prefeitura oferece como apoio a Coordenadoria de Apoio dos Órgãos Colegiados - Caoc, que desempenha papel fundamental no funcionamento do Conselho, pois disponibiliza uma secretaria-executiva ao CMMA, que garante o bom funcionamento das reuniões, suas convocações, a organização documental, o acompanhamento e a gravação das reuniões para a confecção das atas, seus 
agendamentos, a organização da sala de reuniões e outras contribuições. Não se pode desconsiderar, também, o fato de que os conselheiros exercem cargo honorífico, não sendo remunerados para tal função, e como em sua grande maioria não são oriundos do serviço público e mesmo os que o são, podem sofrer pressão sobre seus afazeres profissionais pessoais.

Pela observação das numerosas condicionantes agregadas às licenças, pode-se perceber que, com o sistema municipalizado, os licenciamentos, atendidas as normas legais, são um processo de negociação da sociedade com o poder público e empreendedores, na procura de melhores condições ambientais e socioeconômicas. Os cuidados depois da concessão da licença são maiores do que aqueles que ocorriam no passado.

\section{Embasamento jurídico - legislação pertinente}

De acordo com a legislação destadual, o licenciamento no Estado passa principalmente pelo crivo do Instituto de Meio Ambiente do Mato Grosso do Sul - Imasul, delegando ao Ceca funções normatizadoras e deliberativas no licenciamento sobre os processos que exijam Estudo de Impacto Ambiental - EIA/Relatório de Impacto Ambiental - Rima, semelhante ao CMMA, que atua principalmente na análise direta dos processos encaminhados pela Prefeitura Municipal que exijam EIA/Rima e/ou oriundos do poder público municipal, além de ter também em suas prerrogativas a função de propor regras ao sistema de licenciamento.

O Estado e o município, desde a criação do Silam, debateram e discordaram de vários aspectos concernentes ao licenciamento municipalizado até a celebração, com a interveniência do Ibama, do termo de cooperação técnica $n .^{\circ}$ 002/2002, aditado a cada dois anos: "O presente termo de cooperação técnica consubstancia-se nas disposições da Lei Federal n. ${ }^{\circ}$ 6.938/81, na Lei Federal n. ${ }^{\circ} 9.605 / 98$, na Resolução Conama n. ${ }^{\circ} 237 / 97$, no Decreto Estadual n. ${ }^{\circ} 10.600$ de 19/12/2001, na Lei Federal n. ${ }^{\circ}$ 8.666/93 e suas alterações, na Lei Municipal n. ${ }^{\circ} 3.612 / 99$, nos estatutos dos partícipes e demais disposições aplicáveis."
O Estado já previa, na Lei . $^{\circ} 2.257$, de 9 de Julho de 2001, que dispõe sobre as diretrizes do licenciamento ambiental estadual, no seu Artigo 14: "Cabe aos municípios o licenciamento ambiental dos empreendimentos e atividades consideradas como de impacto local, bem como aquelas que lhes forem delegadas pela Fundação Estadual de Meio AmbientePantanal por instrumento legal ou convênio"; e, no seu parágrafo único: "A Fundação Estadual de Meio Ambiente-Pantanal proporá, em razão da natureza, características e complexidade, a lista de tipologias dos empreendimentos ou atividades consideradas como de impacto local, os quais deverão ser aprovados pelo Conselho Estadual de Controle Ambiental", a possibilidade desse tipo de delegação.

Através da análise do Inquérito Civil n. ${ }^{0}$ 014/2005, referente a loteamento, foi extraído dos autos que os promotores de Justiça e a procuradora da República que o subscrevem, além de detectarem erros no processo, questionam a competência do município em licenciar, apontam as falhas do Estado em aceitar o licenciamento municipal sem o devido estabelecimento dos critérios para tal e alegam a inconstitucionalidade do Conama em legislar por meio de resoluções, extrapolando suas funções.

Percebe-se que toda a linha de raciocínio dos promotores e da procuradora de Justiça dá-se fundamentada no questionamento da constitucionalidade da Resolução 237/97 do Conama, que respalda os Sistemas Municipais de Licenciamento Ambiental no Brasil e, consequentemente, em Campo Grande. No entanto, a Constituição Federal brasileira, lei maior do país, diz que a federação, Estados e municípios têm poder concorrente na proteção do ambiente, abrindo espaço para o licenciamento municipal.

Mas, quando o Ministério Público se preocupa, com razão, com a lisura do processo de licenciamento municipalizado, pelo risco do autolicenciamento, não se pode esquecer que isso pode também ocorrer nos âmbitos federal e estadual. O que garante a lisura, além da vigilância do Ministério Público no cumprimento das leis, é exatamente a participação cada vez maior da sociedade civil organizada nesse processo, como 
ocorre no Ceca de Mato Grosso do Sul e no CMMA de Campo Grande. Portanto, pode-se concluir que, dirimidas as questões legais, é extremamente legítima e saudável a proposta descentralização do processo de gestão ambiental para o fortalecimento do Sisnama, de acordo com o Relatório Nosso Futuro Comum (1991): "As difíceis opções necessárias à obtenção de um desenvolvimento sustentável dependerão do apoio e do envolvimento de público bem informado, de organizações não-governamentais, da comunidade científica e da indústria. Todos eles deveriam ter ampliado seus direitos, suas funções e sua participação no planejamento, na tomada de decisões e na implantação de projetos desenvolvimentistas (CMMAD, 1991)." As válidas preocupações do Ministério Público quanto ao licenciamento pelo município podem redundar no afastamento do nível local das decisões, deixando-as para o Estado ou mesmo a União, instâncias que estão distantes dos problemas, alijando a participação da sociedade local. Da mesma forma que o licenciamento municipal, o licenciamento em outras instâncias também pode ser manipulado e está sujeito a mais falhas, principalmente porque não conhecem profundamente a problemática local.

Outro aspecto a considerar é que cada processo, ao passar pelo crivo de uma comissão técnica multidisciplinar, uma consultoriajurídica e um conselho com representantes da sociedade civil organizada, estará mais protegido de possíveis atos de corrupção, dificultando a manipulação de licenças ambientais. Falhas sempre podem ocorrer, mas da forma como é feito, atualmente, o licenciamento dificulta fraudes.

\section{Limitações do conselho}

O maior problema no funcionamento do conselho fica no cumprimento das condicionantes após a obra ou instalação de empreendimentos, principalmente no caso em que o poder público é o principal interessado, obrigando a se pensar num sistema de fiscalização que seja eficiente. Torna-se imprescindível que as Licenças de Instalação e Licenças de Operação também passem pela deliberação do CMMA, pois apenas a Licença
Prévia é deliberada no conselho municipal. A necessidade de monitoramento e acompanhamento dos empreendimentos após a licença prévia é evidente nas deliberações do conselho, como na sua $60{ }^{a}$ reunião extraordinária, de 26/11/1999, na manifestação sobre a necessidade de relatórios mensais pós-licença para acompanhamento de obras de desvio ferroviário; em sua 66. ${ }^{\mathrm{a}}$ reunião ordinária, que fala da necessidade de acompanhamento da qualidade da água no licenciamento do macroanel rodoviário; e em sua 129. ${ }^{a}$ reunião ordinária, de 18/09/2003, que prevê o monitoramento do ar, água e solo, na implantação de polo industrial. Esses documentos mostram a preocupação dos conselheiros com o que acontece após o licenciamento de que participam.

A inoperância até o momento do Fundo Municipal do Meio Ambiente é um problema a ser resolvido; ele poderia financiar o apoio necessário ao CMMA para acompanhar todas as etapas do licenciamento ambiental. O Decreto 7.884, de 30/7/1999, precisa ser posto em prática e o fundo, regulamentado, para que se permita o uso dos recursos da compensação ambiental emmelhorias para a qualidade do ambiente e da população do município.

É difícil, com base apenas nos dados levantados neste trabalho, avaliar se a atuação do Conselho de Meio Ambiente trouxe ganhos ambientais para o município, masé inegável o acréscimo de exigências no licenciamento quando o processo passa por sua deliberação. Os dados também mostram alguns ganhos, como no caso do licenciamento do polo empresarial, que ocorreu durante a 87. . reunião ordinária, em 5/7/ 2001, em que o conselho obrigou o município a apresentar, discutir e defender o projeto proposto. A ampla participação de representantes da sociedade civil organizada mostra algumas conquistas, e isso pode ser melhorado com a ampliação da participação de entidades de pesquisa e ensino, mais representantes de outros segmentos especializados da sociedade, como outras instituições de nível superior. Recentemente, a capacitação de membros de Conselhos de Meio Ambiente tem sido proposta pelas agências governamentais. 
Outro tipo de atividade importante para o município, que não é deliberada no CMMA, são os loteamentos. Há inclusive questionamento do Ministério Público ao Silam, sobre empreendimento habitacional que foi licenciado sem deliberação do CMMA. Com certeza, se houvesse a intervenção dos conselheiros municipais, os aspectos de localização seriam questionados, como ocorreu no caso de projeto de urbanização de fundo de vale, onde a prefeitura realizou um desvio de trajeto, para não transpor uma Reserva Particular do Patrimônio Natural (RPPN) daFUFMS, solicitada pelo representante da própria Universidade no conselho, deliberada pelo plenário e acatada pela prefeitura. A compatibilização das licenças ambientais e urbanísticas no processo de municipalização do licenciamento ambiental se faz urgente. Um dos mais antigos conselhos municipais de Campo Grande, o Conselho Municipal de Desenvolvimento Urbano - CMDU, atua alheio ao CMMA, tratando de questões do parcelamento do solo. Seria mais produtivo se esses conselhos se fundissem tratando, num único fórum, de todos os temas ambientais e urbanísticos.

Houve importantes avanços com a criação da Secretaria Municipal do Meio Ambiente e com a ampliação da participação de segmentos da sociedade na última alteração da composição do CMMA, e retrocessos, pela diminuição da participação espontânea dos conselheiros, em pedir vistas dos processos. Em nenhum dos processos analisados o tempo de análise superou 30 dias, atrasando ou burocratizando a licença ambiental.

\section{Considerações Finais}

A legislação existente é abrangente e tem sido suficiente para dar suporte e legitimar o licenciamento ambiental municipalizado.

Porém, em nível municipal, é urgente que seja regulamentado e efetivado o Fundo Municipal do Meio Ambiente, instituído pela Lei n. ${ }^{\circ}$ 3.612, de 30 de abril de 1999, que possibilitaria investimentos na estrutura de fiscalização e controle ambiental do município. Sem o fundo, os recursos advindos de multas, compensação e licenças ambientais são recolhidos ao Tesouro
Municipal e destinados às prioridades dos dirigentes do momento.

O Decreto n. ${ }^{\circ} 7.884$, de 30 de julho de 1999, que regulamentou a Lei n. ${ }^{\circ}$ 3.612, de 30 de abril de 1999 e criou o Silam, no seu Art. 15 não garante ao CMMA poder deliberativo sobre outros empreendimentos que possam ser considerados relevantes por esse conselho, restringindo a deliberação somente a aqueles empreendimentos relacionados. Deverá haver uma modificação na legislação que dê essa prerrogativa de pedir vistas e deliberar, após anuência da plenária, sobre qualquer processo em trâmite na Prefeitura Municipal de Campo Grande. De acordo com Cezare (2009), um conselho deve possuir caráter consultivo e deliberativo, pois assimele pode decidir sobre políticas públicas, interferindo sobre os processos ambientais de interesse da população.

Apesar dos problemas, o licenciamento ambiental municipal tem levado a decisões democráticas, à participação da sociedade nas ações que, de alguma forma, afetam sua qualidade de vidae a sustentabilidade do planeta. Chama a atenção nos processos avaliados que, quando não havia parecer técnico da Secretaria Municipal do Meio Ambiente, não ocorreu aprovação de licenças ambientais por parte dos conselheiros. Tambémemnenhum caso houve redução de exigências, sendo que na maioria existiu aumento do número de condicionantes para o licenciamento ambiental.

\section{REFERÊNCIAS}

BREDARIOL, C.S.; VIEIRA, L. Cidadania e política ambiental. Rio de Janeiro: Record, 1998. $171 \mathrm{p}$.

\section{BUAINAIN, M.S.C.N. (Org.). Legislação} municipal de interesse ambiental de 1977 a janeiro de 1997. Campo Grande: Instituto Municipal de Planejamento Urbano e Meio Ambiente (PLANURB), 1998. 448p.

CAMPO GRANDE. 100 anos de construção. Campo Grande: Matriz Editora, 1999. 420p. 
Atuação do Conselho Municipal do Meio Ambiente...

CARVALHO, J.C. Poder Executivo. In. TRIGUEIRO, A. (Coord). Meio Ambiente no século 21: 21 especialistas falam da questão ambiental nas suas áreas de conhecimento. Rio de Janeiro: Sextante, 2003. p. 258-273.

CEZARE, J.P. Conselhos municipais e governança: uma análise do conselho de representantes de Paranapiacaba e Parque Andreense do Município de Santo André-SP. 176f. Dissertação (Mestrado em Saúde Publica), Universidade de São Paulo, São Paulo, 2009.

CMMAD. Comissão Mundial sobre Meio Ambiente e Desenvolvimento. Nosso futuro comum. Rio de Janeiro: FGV, 1991. 430p.

DOMBROWSKI, O. O poder local, hegemonia e disputa: os conselhos municipais em pequenos municípios do interior. Revista de Sociologia e Política, v. 16, n. 30, p. 269-281, 2008.

DOWBOR, L. Descentralização e meio ambiente. In: BURSZTYN, M. (Org.). Para pensar o desenvolvimento sustentável. São Paulo: Brasiliense, 1993. p.103-142.

FERREIRA, J.S.W. Globalização e urbanização subdesenvolvida. São Paulo em Perspectiva, v. 4, n. 14 , p. 10-20, 2000.

FURRIELA, R.B. Democracia, cidadania e proteção do meio ambiente. São Paulo: Annablume, FAPESP, 2002. 193p.

GONÇALVES, A.F. O conceito de governança. In: CONGRESSO NACIONAL CONPENDI, 14. 2005, Fortaleza. Anais... Fortaleza, 2005.

Disponível em: http://www.conpedi.org.br/manaus/ arquivos/Anais/Alcindo\%20Goncalves.pdf. Acesso em: 10 de ago. 2011.

GOHN, M.G. Conselhos gestores e participação sociopolítica. São Paulo: Cortez, 2007. (Coleção questões da nossa época; v. 84),

IBGE. Instituto Brasileiro de Geografia e Estatística. Perfil dos municípios brasileiros: meio ambiente, 2002. Rio de Janeiro: IBGE. 2005. Disponível em URL <http://www.ibge.gov.br>.Acesso em: 11 mar.2010.

JACOBI, P.R. Meio ambiente e sustentabilidade. In: CEPAM (Org.). O município no século XXI. São Paulo: CEPAM, 1999. p. 175-184.

JACOBI, P.R. Participação cidadã na gestão ambiental no Brasil. In: ZICCARDI, A. (Org.). Participación ciudadana y politicas sociales en el ámbito local. México: Instituto de Investigaciones Sociales, 2004. p. 317-334. v. 1.

JACOBI, P.R. Participação na gestão ambiental no Brasil: os comitês de bacias hidrográficas e o desafio de fortalecimento de espaços públicos colegiados. In: ALIMONDA, H. (Org.). Los tormentos de la matéria: aportes para una ecologia politica latinoamericana. Buenos Aires: Clacso Libros, 2006. p. 169-194.

PHILIPPI JR, A.; MALHEIROS, T.F.; SALLES, C.P.; SILVEIRA, V.F. Gestão Ambiental Municipal: subsídios para a estruturação de sistema municipal de meio ambiente. Salvador: Centro de Recursos Ambientais, 2004a.128p.

PHILIPPI JR, A.; BRUNA, G.C.; ROMÉRO, M.A. Curso de Gestão Ambiental. São Paulo: Manole, 2004b. 1050p.

OLIVEIRA, P.T.S.; AYRES, F.M.; PEIXOTO FILHO, G.E.C.; MARTINS, I.P.; MACHADO, N.M. Geoprocessamento como ferramenta no licenciamento ambiental de postos de combustíveis. Sociedade e Natureza, v. 20, n. 1, p. 87-99, 2008 . 
ROLNIK, R. O que é cidade. São Paulo:

Brasiliense, 1995. 86p. (Coleção primeiros passos, 203)

SÃO PAULO (Estado). Secretaria do Meio Ambiente. CONSEMA: dez anos de atividades. São
Paulo: Secretaria do Meio Ambiente, 1993. 695p.

SLOMSKI, V.; MELLO, G.R.; TAVARES FILHO, F.; MACEDO, F.Q. Governança corporativa e governança na gestão pública. São Paulo: Atlas, 2008. v. 1. 198p.

RECEBIDO EM 2/6/2011

ACEITO EM 29/6/2011 